\title{
Workplace spirituality and organizational citizenship behavior: Evidence from banking industry
}

\author{
Mohammad Ghorbanifar* and Fereydoon Azma
}

Department of Management and Accounting, Aliabad Katoul Branch, Islamic Azad University, Aliabad Katoul, Iran

\section{H R O N I C L E}

Article history:

Received January 20, 2014

Accepted 5 July 2014

Available online

July 142014

Keywords:

Workplace spirituality

Organization citizenship behavior

Bank employees

\begin{abstract}
A B S T R A C T
This paper studies the relationship between workplace Spirituality and Organization Citizenship behavior (OCB) in banks located in province of Sari, Iran. The statistical population of research includes the employees of Sari's Banks including Melli, Ghavamin, Saderat, Keshavarzi, Mellat,Tejarat, Saman, Parsian, Sarmaye, Pasargad and Karafarin. We used a questionnaire with 45 questions as an instrument for collecting research data. The questionnaire was designed based on workplace spirituality (Milliman et al., 2003) [Milliman, J., Czaplewski, A., \& Ferguson, J. (2003). Workplace spirituality and employee work attitudes, an exploratory empirical assessment. Journal of Organizational Change Management, 16(4), 426-447.] and organizational citizenship behavior (Podsakoff et al., 1990) [Podsakoff, P., MacKenzie, S., Paine, J., \& Bachrach, D. (2000). Organizational citizenship behaviors: A critical review of the theoretical and empirical literature and suggestions for future research. Journal of Management, 26(3), 513-563.]. Findings show that there was a meaningful relationship between workplace Spirituality and Organization Citizenship behavior. The results also indicated that there was a positive relationship between work spirituality and Organization Citizenship behavior in Sari's Bank.
\end{abstract}

\section{Introduction}

During the past few years, there have been increasing interests on employees' work-related behaviors, which influence on organizational effectiveness. The focus was on role-based performance to consider the relationship between employees' organizational behavior declared in job explanation and organization formal role. However, recently, researchers have differentiated between in-role performance and extra-role performance. In fact, the extra-role performance is beyond job descriptions of employees. These behaviors are voluntary and most of the times, there is not a predefined organization bonus for them (Organ, 1988). Researchers have emphasized on the effect of extra-role performance on organization effectiveness. One of the most known forms of extra-role

*Corresponding author.

E-mail addresses: ghorbanifar.m2@gmail.com (M. Ghorbanifar) 
performance is the organization citizenship behavior (OCB) (Bateman \& Organ, 1983; Organ, 1988). The concept of organizational citizenship behavior was the subject of many studies and its research and practical importance is increasing. The research literature shows three major trends in the field of organizational citizenship behavior; the first trend concentrates on Antecedent and experimental examination of the antecedents of OCB. The most important antecedents of OCBs are work satisfaction, organization obstruction, organizational identity, organizational justice, trust, leadership, leader - follower exchanges, etc. (Podsakoff et al. 2000). Recent studies consider the concept of workplace Spirituality as a determinant of organizational citizenship behavior. The elements of workplace spirituality considered in this research are meaningful work, sense of community, alignment of values. The main question of this study is:

\section{Main hypothesis: Is there any meaningful relationship between workplace Spirituality and Organizational Citizenship Behavior?}

Secondary questions of research consider the relationship between dimensions of workplace Spirituality (3 dimensions) and dimensions of organizational citizenship behavior ( 5 dimensions).

\section{Literature Review}

One of the most important trends in business and management suggested in the mid-90s is to focus on spirituality of employees in organization. The reason makes organizations be interested in workplace spirituality is the increase on the organizational effectiveness. The experimental evidences show the positive relationship between workplace spirituality and creativity (Freshman, 1999), honesty and trust within organization, Increased sense of personal success, organizational commitment, job different behaviors such as job satisfaction, occupational participation, decreasing the desire to quit, and organization- based self-esteem. There are various definitions and perspectives about the personal nature of spirituality. In this survey, we concentrate on the definition of workplace spirituality suggested by Ashmos and Duchon (2000) as "Understanding and identifying that the dimension of the inner life of employees, that it can be developed by doing meaningful works in life". Based on this definition, those two researchers with help of factor analysis method created a questionnaire with seven main aspects in order to help researchers to measure the workplace spirituality. Milliman et al. (2003) chose three aspects of these seven aspects, which fit the individual level, group level, and organizational level, and use these aspects in their study. These three aspects include meaningful work at the individual level, sense of community at the group level, and alignment with organizational value at the organizational level.

An important aspect of the spirituality in work incorporates a deep sense of meaning and purpose at work. This aspect of workplace spirituality detects how employees interact in their daily work at the individual level. Expressing spirituality in work also incorporates this hypothesis that every person has intrinsic motivation, facts and signs for performing various activities, which would make the life meaningful. Another basic aspect of workplace spirituality includes a strong bound with other as a type of feeling of deep solidarity. This perspective of workplace spirituality happens at the group level of human behavior and implies the interactions between the employees and their colleagues. Solidarity at work based on the belief that people know each other in commonality, and they also know that there is a relationship between the inner self of each one and inner self of others (Milliman et al., 2003). This level of workplace spirituality includes Mental, emotional and spiritual connections among employees in the business group. The third aspect of workplace spirituality is experiencing a strong insight of alignment between personal values of employees with the mission, duty and values of organization. This aspect of workplace spirituality includes interaction of employees with larger organizational objectives (Mitroff \& Denton, 1999). The alignment of organizational values specifies that the people believe that the managers and the employees in organization have common interests, and organization consider employees welfare and their solidarity (Ashmos \& Duchon, 2000). 
Organ (1988) introduced the phrase organizational citizenship by considering different concepts such as willingness to cooperate, and the distinction between performance based on role, and performance based on innovative and spontaneous behaviors. Firstly, the studies largely conducted to understand the fact that although it has an obvious impact on the organization performance, but they were ignored in performance evaluation systems. In fact, in the initial interpretations, it was significant that the organizational citizenship behavior includes behaviors outside of the scope of job. Of course, gradually along with the development of the concept of organizational citizenship behavior, it became clear that the distinction between activities within the scope of the job and outside the scope of the job was not crystal clear. Therefore, organizational citizenship should be defined in flexible way (Bienstock et al., 2003). One of the primary definition that has been adopted by many researchers is raised up by Organ (1988) is as "organizational citizenship behavior includes discretionary behavior of employees which is not part of their official duties, and directly will not be considered by the official reward system organization but increases the overall effectiveness of the organizations' rate". The other point, that likely predictions and rates of these behaviors with the help of behaviors and status of the employees are better than the common criteria evaluation of performance, because voluntary and optional aspects of these behaviors are much more prominent than the normal behavior of a job (Farh et al., 2004). Among all dimensions of organizational citizenship behavior, the most important dimensions include altruism, conscientiousness, courtesy, sportsmanship, civic virtue. These five dimensions were suggested by Organ (1988). Podsakoff et al. (1990) created a standard scale for each of these dimensions with help of factor analysis. Many researchers used these scales for measuring organizational citizenship behavior in later years (Organ, 1988).

There are many studies conducted on the variables of citizenship behavior and spirituality, but there is no study on the relationship of these two variables. Mortazavi and Kargozar (2011) studied the factors influencing the occurrence of customer oriented citizenship behavior among nurses. They concluded that since there is procedural justice in shaping job satisfaction and organizational commitment, and because it has more effect compared with other dimensions of justice, therefore, the regulatory policies and procedures shall be in a way that nurses considered them fair and nondiscriminatory. Ahmadi and Khoddami (2010) studied the organizational citizenship behavior by taking advantage of variables of "general citizenship behavior" and "spirituality" as independent variables, and "organizational citizenship behavior" as dependent variable and through triple headlights career "participation in decision making", "job satisfaction" and "organizational commitment" as mediator variable in Iran insurance joint-stock company. The result of the research showed that the both general citizenship behavior and spirituality in total had a positive relationship with job trends and dimension of organizational citizenship behavior, which includes two general dimension dedication and obedience. Beikzad et al. (2010) studied the effectiveness of workplace spirituality on organizational citizenship behavior of employees in five areas of city of Tabriz. The result of this study showed that workplace either at individual level or at group level or at the organizational one, has an impact on citizenship behavior of the ministry of education employees in five areas of Tabriz city. Nikpour et al. (2010) studied the relationship between the workplace spirituality and organizational citizenship behavior of employees in Kerman martyr foundation. The result of the study showed that there was a significant relationship between significant variables of work, solidarity with others, and alignment with organizational values and organizational citizenship behavior. Farhangi et al. (2007) studied the spirituality in workplace and its role in improving the organizational citizenship behavior among the employees of Tehran university colleges. The result of this study showed that there was a significant relationship between workplace spirituality and organizational citizenship behavior. Although the concept of organizational citizenship behavior in the last 20 years has been the topic of many studies and its importance was introduced, but the foreign studies rarely pay attention to the relationship between the variables of organizational spirituality and organizational citizenship behavior. Some of the studies have focused on the prediction and experimental test of factors creating the organizational citizenship behavior. 
In this regard the factor such as job satisfaction, organizational commitment, organizational identity, organizational justice, trust, leadership, the relationship between leader and followers have been suggested as factors creating organizational citizenship behavior Podsakoff et al. (2000). Milliman et al. (2003) studied the relationship between the variables of workplace spirituality and factors creating, and factors cause job attitudes. The result of this study showed that the workplace spirituality had an effect on the variables of job satisfaction, organizational commitment, career partnership, reducing the desire to quit the job, etc. Alotaibi (2005) studied the relationship between the variables of job satisfaction, understanding of justice, organizational commitment, and organizational citizenship behavior. In this study, Alotaibi found that the only relationship it was between the organizational commitment and organizational citizenship behavior. Pawar (2009) identified the most important predictors of workplace spirituality in the field of organizational behavior. Chen and Yang (2012) studied the relationship between spiritual leadership and organizational citizenship behavior. The result of this study showed that there is a significant relationship between spiritual leadership and dimension of organizational citizenship behavior.

\subsection{Research Hypothesis's}

Main Hypothetic of Research: There is a relationship between employee's work spirituality with Organizational Citizenship behavior Sari's Bank.

Secondary Hypothetic:

1. There is a relationship between employees' Meaningful work with Organizational Citizenship behavior in Sari's Bank.

2. There is a relationship between employees' sense of community with Organizational Citizenship behavior in Sari's Bank.

3. There is a relationship between employees' Alignment with organizational values with Organizational Citizenship behavior in Sari's Bank.

4. There is a relationship between workplace spirituality and Conscientiousness in Sari's Bank.

5. There is a relationship between workplace spirituality and Sportsmanship in Sari's Bank.

6. There is a relationship between workplace spirituality and Civic Virtue in Sari's Bank.

7. There is a relationship between workplace spirituality and Courtesy in Sari's Bank.

8. There is a relationship between workplace spirituality and Altruism in Sari's Bank.

\section{Research methodology}

This is applied study, and the method used in this study is descriptive- survey one. The questionnaire is the main tool for collecting data in this study. The questionnaire used in this study has two sections. The first section of the questionnaire related to workplace spirituality which has been designed by using the scale of spirituality in workplace belongs to Milliman et al (2003). This questionnaire measures three dimensions of significant work (6 questions), the feeling of solidarity with others ( 7 questions), and alignment with organization values (8 questions). The second section of the questionnaire is related to organizational citizenship behavior which has been based on the study done by Padsakoff et al. (1990). The questionnaire of organizational citizenship behavior measures five dimension of conscience (5 questions), sportsmanship (5 questions), civic virtue (4 questions), courtesy (5 questions), and altruism (5 questions). In total, the questionnaire of the current study has 45 main questions, and 5 ancillary questions. The five options of Likert scale, which is considered to be one of the most common measuring scales has been used to design the questionnaire questions. 
Opinions of professors and experts in fields related to this topic have been used In order to assess the validity of the study questionnaire. In this study, the method of Cronbach' Alpha has been used in order to assess the questionnaire reliability. With the intention of measuring the questionnaire reliability, 25 questionnaires have been distributed among the employees of Banks in Sari County. After collecting the data, its reliability has been measured by Cronbach's Alpha test. Since the Alpha value obtained for the workplace spirituality questionnaire was (0.92) and for organizational citizenship behavior was $(0.85)$, which is more than 0.70 , so the questionnaire has required reliability.

For analyzing the data, the descriptive statistic's indicators, such as frequency, percentage, frequency distribution tables, mean and standard deviation had been used in this study. Regarding the part of inferential statistics, correlation tests have been used. The relationship between two main variables has been obtained by using SPSS software, Structural equation modeling, and LISREL 8.53 software.

Statistical society in this study is employees of Banks in Sari County. These banks include Meli, Ghavamin, Saderat, Keshavarzi, Mellat, Tejarat, Saman, Parsian, Sarmaye, Pasargard, and Karafareen Bank. In this study the simple random sampling method used to select 200 persons as sample from statistical society consist of 2000 persons.

\section{Research Findings}

According to descriptive and demographic analysis of data, $67 \%$ of Banks in this study are stateowned bank. $71 \%$ of the respondents are male, and $58.5 \%$ of them were in age between $25-25$. In addition, $58 \%$ of respondents hold a Bachelor degree; also $36 \%$ have work experience between 5 to 10 years. Most of the respondents namely $57 \%$ were employees.

In order to test the hypotheses of the survey, according to the results of correlation coefficient stated in Table 1, it is clear that there was a significant and positive relationship at the level of certainty $99 \%$ between all the factors of workplace spirituality and organizational citizenship behavior. In addition, there was a significant and positive relationship between workplace spirituality and all dimensions of organizational citizenship behavior in the Banks of Sari County. Therefore, with 99 percent certainty we can say that all the study confirm the hypothesis.

Table 1

The results of correlation between OCB and workplace Spirituality Dimensions

\begin{tabular}{lcc}
\hline & \multicolumn{2}{c}{ Organization Citizenship behavior } \\
& Correlation coefficient (r) & Significance level (p) \\
\hline Workplace Spirituality & 0.577 & 0.000 \\
Meaningful work & 0.511 & 0.000 \\
Sense of community & 0.474 & 0.000 \\
Alignment with organizational values & 0.473 & 0.000 \\
\hline
\end{tabular}

Table 2

The results of correlations between workplace Spirituality and OCB Dimensions

\begin{tabular}{lcc}
\hline & \multicolumn{2}{c}{ Workplace Spirituality } \\
\cline { 2 - 3 } & Correlation coefficient (r) & Significance level (p) \\
\hline Conscientiousness & 0.437 & 0.000 \\
Sportsmanship & 0.285 & 0.000 \\
Civic Virtue & 0.481 & 0.000 \\
Courtesy & 0.435 & 0.000 \\
Altruism & 0.353 & 0.000 \\
\hline
\end{tabular}




\subsection{Structural Equation Model(SEM)}

In the current study, Fig. 1 shows structural equation model used to examine the hypotheses of the survey. It also shows the coefficients of the implementation of SEM model. In addition, Table 3 demonstrates some basic statistics associated with SEM implementation.

Table 3

The structural equation model of workplace spirituality and Organizational Citizenship Behavior

\begin{tabular}{ccccc}
\hline Variance error & Standard index $(\mathrm{R})$ & R-Square & P-value & Result \\
\hline 0.53 & 0.64 & 0.55 & 0.0053 & Accepted \\
\hline GFI & AGFI & RMSEA & Chi-Square & \\
\hline 0.91 & 0.91 & 0.072 & 38.37 & \\
\hline
\end{tabular}

According to the results of Table 3, standard coefficient (R) suggested relationship between the variable of spirituality in workplace and organizational citizenship behavior. The other statistics such as R-Square value, the coefficient of determination, $\mathrm{T}$ value, and model fit indices such as Chisquare, GF, RMSEA, etc. are within acceptable limits.

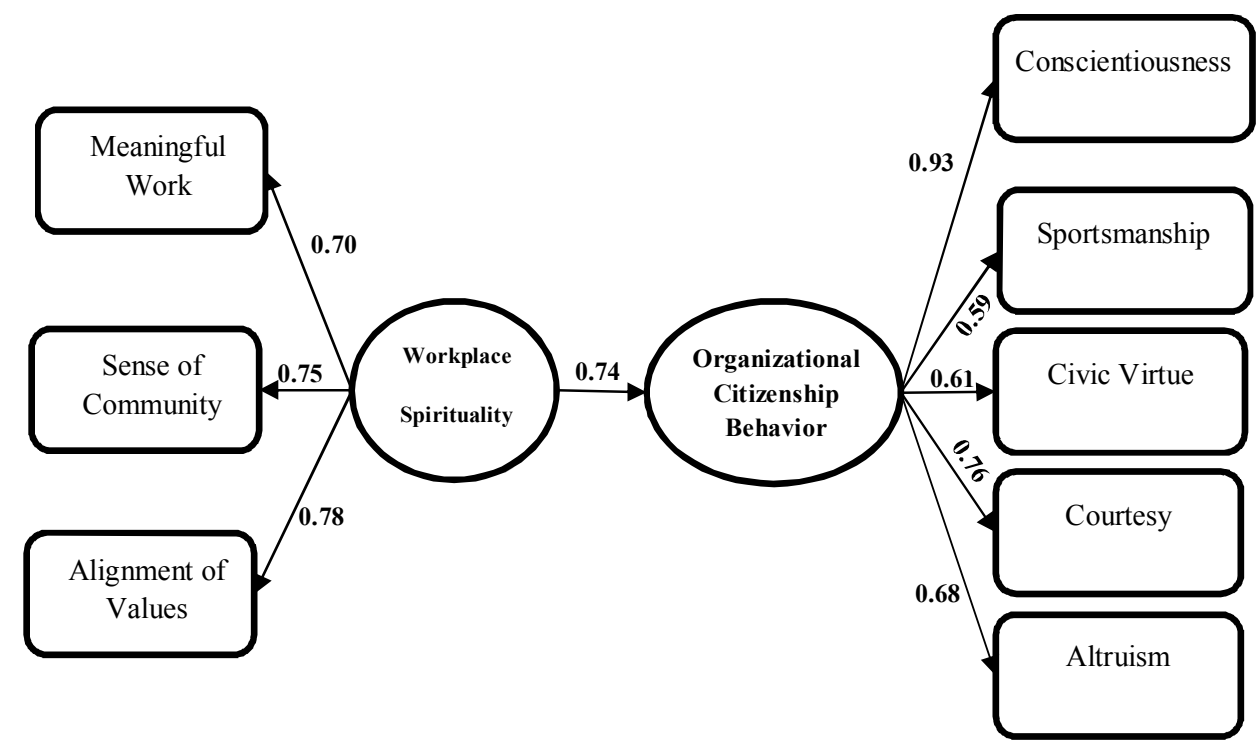

Fig. 1. The structural equation model of workplace spirituality and Organizational Citizenship behavior using the LISREL software

First, since the value of $t$ is significant, the first hypothesis will be confirmed in certainty of 99 . Second, the validity and suitable fitness of model will be confirmed, because the value of Chi-square, the value of RMSEA, and the ratio of Chi-square test with less degree of freedom and value of GFI and AGFA also over than 99. Third, the determination coefficient equal to 0.55 . This means that $55 \%$ of organizational citizenship behavior changes can be explained with spirituality in a workplace. According to this model, it can be said that the spirituality in the workplace in the target community in the certainty level of $99 \%$ causes organizational citizenship behavior.

\section{Conclusion and implications}

The result of this study showed that there was a positive and significant relationship between Employees' spirituality in the workplace and organizational citizenship behavior in Banks of Sari County located in north region of Iran. In addition, the results show that there was a significant and 
positive relationship between different parameters involved in workplace spirituality: meaningful work for employees, employees feeling of solidarity, and alignment of employees of banks of Sari County with organization values and with organizational citizenship behavior. The results also showed that there was a significant and positive relationship between workplace spirituality with all dimensions of organizational citizenship behavior. These dimension are: consciousness, sportsmanship, civil virtue, courtesy, and altruism. In addition, according to the model obtained of analysis of structural equation using LISREL software it can be stated that the spirituality in workplace in target community and in certainty level of $99 \%$ can cause organizational citizenship behavior, and this itself accrediting the test of study hypothesis using correlation tests. Based on this analysis, it is possible to study the context of relationship between spirituality in workplace and organizational citizenship behavior.

The findings illustrate that there was a significant and positive relationship between workplace spirituality and organizational citizenship behavior. This kind of behaviors does not mean that the employees will directly get a reward, even employees themselves do not expect to receive reward, and these behaviors can help organization and managers to improve the organizational image. Therefore, it can be expected that the organizations that have Manpower with the rate of more workplace spirituality, and they also promote this kind of spirituality, have more chances to success in today's competitive world. Because in all cases, there is no any prediction for organizational behavior, and in some cases, employees must do their best to prop up the organization without expecting to receive a reward. In addition, the relationship between workplace spirituality and organizational citizenship behavior specifies this point that in order to increase citizenship behavior the spirituality in the workplace must strengthen, and workspace that can boost spirituality must be created. The training and education that increase the awareness of spirituality necessity in organization, and help employees in identifying their importance and position in organization, is so vital. Moreover, excellent manager in organization should show his support and protection in deeds and words. Promoting spirituality in organization provides a context for increasing the organization citizenship behavior. Promoting spirituality in organization provides a context for increasing the organization citizenship behavior. The result of current study is completely similar to the result of the study of Nikpour et al. (2010). Beikzad et al. (2010) reported that the workplace spirituality and its entire dimension had a significant relationship with organizational citizenship behavior. Moreover, the result of the study of Farhangi et al. (2007) illustrated that there was a significant and positive relationship between spirituality in workplace, organizational citizenship behavior and all its dimensions.

\section{References}

Ahmadi, A., \& Khoddami, A. (2010). The Model for public citizenship behavior, Spirituality and Organizational Citizenship behavior in Iran Public sector: the case of Iran Insurance Company. The Journal of Management Researches, 107-128.

Alotaibi, G. (2005). Antecedents of organizational citizenship behavior. A study of public personnel in Kuwait. Public Personnel Management, 30(3), 350-363.

Ashmos, D., \& Duchon, D. (2000). Spirituality at work: a conceptualization and measure. Journal of Management Inquiry, 9(2), 134-145.

Bateman, T., \& Organ, D. (1983). Job satisfaction and the good soldier: The relationship between affect and employee citizenship. Academy of Management Journal, 26, 587-595.

Beikzad, J., Hamdellahi, M., \& Hamdellahi, K. (2010). The influence of workplace Sprituality on Organizational Citizenship behavior of Tabriz Amoozesh va Parvarsh Employees,. Quarterly Journal of Leadership, 4, 23-24.

Bienstock, C., DeMoranville, C., \& Smith, R. (2003). Organizational citizenship behavior and service quality. Journal of Service Marketing, 17(4), 357-373. 
Chen, C.-Y., \& Yang, C.-F. (2012). The Impact of Spiritual Leadership on Organizational Citizenship Behavior: A Multi-Sample Analysis. Journal of Business Ethics, 105, 107-114.

Farh, J., Circa, C., \& Organ, D. (2004). Organizational citizenship behavior in the people's republic of china. Organization Science, 15, 241-253.

Farhangi, A., Fattahi, M., \& Vasegh, B. (2007). Workplace Sprituality and improving organizational behavior Improvement. Management Culture, 13, 5-36.

Freshman, B. (1999). An exploratory analysis of definitions and applications of Spirituality in the workplace. Journal of Organizational Change Management, 12(4), 318-327.

Milliman, J., Czaplewski, A., \& Ferguson, J. (2003). Workplace spirituality and employee work attitudes, an exploratory empirical assessment. Journal of Organizational Change Management, 16(4), 426-447.

Mitroff, I., \& Denton, E. (1999). A Spiritual Audit of Corporate America: A Hard Look at Spirituality, Religion, and Values in the Workplace. San Francisco, CA: Jossey-Bass.

Mortazavi, S., \& Kargozar, N. (2011). The study of Relationship between Organizational Justice, job Satisfaction and emotional commitment and Nurses organizational citizenship behavior: the case of Imam Reza Hospital. The Journal of Zanjan medical science University, 80, 84-97.

Nikpour, A., Manzari Tavakkoli, A., \& Hosseinnezad, M. R. (2010). The relationship between workplace Spirituality and Organizational Citizenship Behaviors in Employees of Kerman Bonyad-e- Shahid Organization. Beyond the management, 16, 155-172.

Organ, D. (1988). Organizational citizenship behavior: The good soldier syndrome. Lexington, MA: Lexington Books.

Pawar, B. (2009). Some of the Recent Organizational Behavior Concepts as Precursors to Workplace Spirituality. Journal of Business Ethics, 88(2), 245-261.

Podsakoff, P., MacKenzie, S., Moorman, R., \& Fetter, R. (1990). Transformational leader behaviors and their effects on followers' trust in leader, satisfaction, and organizational citizenship behavior. Leadership Quarterly, 1(2), 107-142.

Podsakoff, P., MacKenzie, S., Paine, J., \& Bachrach, D. (2000). Organizational citizenship behaviors: A critical review of the theoretical and empirical literature and suggestions for future research. Journal of Management, 26(3), 513-563. 